\title{
1. Global + local logistics: Asian-Pacific Rim perspectives
}

The 'seven Rs' (of logistics) stand for having the right product, in the right quantity, in the right condition, at the right place, at the right time, for the right customer, at the right cost (Wisner et al., 2008, 358).

In 1950 the impoverished and economically stagnating coastal arena stretching from Russia to the Indonesian archipelago was not designated as the 'Asian-Pacific Rim' but subsumed under the British term 'the Far East', an expression covering the lands beyond India, but excluding Australasia or Oceania. Despite the Far East's historical importance in international trade during both the pre-colonial and the colonial eras, there was no pressing need for perspectives on logistics. At that time logistics was still a branch of military science, having to do with procuring, maintaining and transporting material, personnel and facilities. There was no formal or integrated concept linking highly fragmented logistics activities with manufacturing and marketing. The terms 'global logistics' and 'local logistics' were not in fashion, nor were container shipping, jumbo jets and the Internet in operation.

Fast-forwarding 60 years to the second decade of the new millennium, the situation has changed dramatically. The Asian-Pacific Rim, covering the archipelago between the Russian Far East and Indonesia and, on occasions, extended to include Oceania, is now a defined area for academic study (Le Heron and Park, 1995). Accounting for two-thirds of the tonnage of international trade and more than half of the total intraregional tonnage, the Rim is now the world's prime economic growth centre (Figure 1.1). Over the intervening period since 1950 logistics itself has been transformed into an activity for studying business organizations, because many of the early operations management (OM) researchers left the military for business, and used their quantitative methods to improve the efficiency of transporting materials and finished products. Global, if not local, logistics has become a prominent topic of study, buoyed by the triple revolution involving container shipping, jumbo jets, and information and communications technology (ICT).

This chapter reviews global logistics patterns to highlight the nature and extent of the Asian-Pacific Rim's involvement in different spheres of 


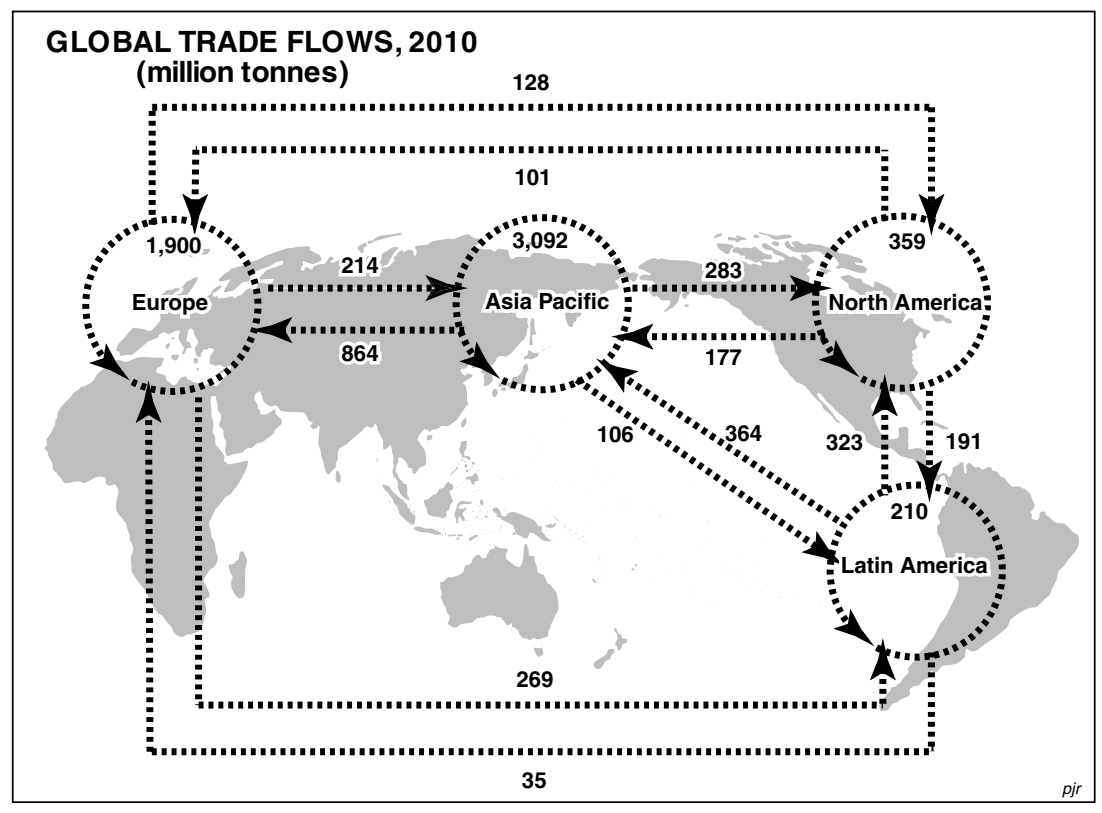

Note: The original diagram has been reorganized to centre on the Asia Pacific region.

Source: Data from DPDHL $(2011,30)$.

Figure 1.1 Major trade flows between the world's supra-regions, 2010

activity - manufacturing and retailing, shipping, air transport and telecommunications - before appraising a range of local logistics policies. The chapter's purpose is to provide a context within which to explore links between global and local logistics by identifying key issues and suggesting appropriate methodologies for exploring them. Insights drawn from the Rim may assist in making comparisons with logistics in the world's other key economic regions, notably Europe and North America. The Rim's logistics arena warrants detailed attention, because the sector's logistics costs as percentage of gross domestic product (GDP) exceed those of both Europe and North America; there is also scope for greater outsourcing because the Rim's revenue from this activity as a proportion of logistics costs is lower than its counterparts (Table 1.1). Before outlining the book's framework for examining the implications of these trends, the broad changes that have occurred in analysing logistics since the 1950s are reviewed; the essential character of global logistics is outlined; the term 'local logistics' is coined; and key features of the Asian-Pacific Rim are highlighted. 
Table 1.1 Estimates of the global logistics market's size, 2012

\begin{tabular}{|c|c|c|c|c|c|}
\hline Region & $\begin{array}{l}\text { Gross } \\
\text { domestic } \\
\text { product }\end{array}$ & $\begin{array}{l}\text { Logistics/ } \\
\text { GDP }\end{array}$ & $\begin{array}{c}\text { Logistics } \\
\text { cost }\end{array}$ & $\begin{array}{l}\text { Outsourced } \\
\text { revenue/ } \\
\text { Logistics } \\
\text { cost }\end{array}$ & $\begin{array}{l}\text { Outsourced } \\
\text { revenue }\end{array}$ \\
\hline & US\$ bn & $\%$ & US\$ bn & $\%$ & US\$ bn \\
\hline $\begin{array}{l}\text { Asian-Pacific } \\
\text { Rim }\end{array}$ & 21881.9 & 12.8 & 2809.8 & 8.6 & 242.7 \\
\hline Europe & 16394.9 & 9.2 & 1504.8 & 10.5 & 158.0 \\
\hline North America & 18676.0 & 8.8 & 1639.6 & 10.5 & 171.2 \\
\hline \multirow[t]{2}{*}{ Other } & 14877.2 & 16.1 & 2396.4 & 4.7 & 113.2 \\
\hline & 71830.0 & 11.4 & 8350.6 & 8.2 & 685.1 \\
\hline
\end{tabular}

Note: Australia and India are included in Asia-Pacific.

Source: Armstrong \& Associates (2013a).

\section{LOGISTICS}

During the 1950s the term 'logistics' was 'borrowed' from military practice to address the neglected issue of getting products promptly to where customers resided. Since then the civilian expression of 'logistics' has been progressively redefined as physical distribution, business logistics, and supply chain logistics, before social logistics was added to the mix.

Physical distribution was invoked to enhance cost economies in marketing that top management had already achieved in production and finance (Drucker, 1962). The task involved integrating seven hitherto separate and independent activities - transport, inventory control, warehousing, packaging, materials handling, order processing and consumer service - into an organized framework with the intention of balancing costs and service in moving goods to maximize customer satisfaction (Smykay et al., 1961). As defined by the National Council of Physical Distribution Management (NCPDM), formed in 1963, the purpose of the physical distribution management (PDM) system was to get the product to the right place at the right time (the first two of the seven Rs of logistics), particularly as the concept of safety stock had been neglected (LaLonde and Dawson, 1969; Glencowets, 1979).

Once this integration had been achieved through the spatial arrangement of plant capacity and warehouse facilities, and the connecting transport linkages, the components could be combined into a simulation 
model aimed at minimizing costs while satisfying marketing requirements (Gilmour, 1974). Adoption and modelling of the combined components of transport and warehousing promised a large-scale cost reduction, and then, when the central management of physical distribution was firmly established and consolidated, the enhanced arrangement provided a competitive advantage to distributors because they were able to offer a superior cost-efficient service. Although the importance of distribution was elevated in strategic decision-making within the firm, attention was concentrated upon the movement of material from the manufacturer to the user, usually finished goods or service parts; there was no coverage of the flow of raw materials and semi-finished components into the vertical manufacturing production process (that is, materials management).

Business logistics was mooted in the 1960s prompted by the need to broaden the activities under discussion and create value for the customer (Plowman, 1964, vii-viii). By the mid-1970s the process involved integrating the multiple sub-functions covered in materials management and physical distribution management under a single umbrella to integrate inbound and outbound flows (Buytenen et al., 1976). This development sought to accommodate increased acceptance of the systems approach, customer demands, multinational distribution, and government influence over distribution policy and practice (LaLonde and Zinszer, 1976).

Operations management had come to the fore in the planning, scheduling and control of activities that transformed inputs into finished goods and services. This led Martin Christopher (1974) to outline a systems engineering approach to resolving logistics issues, and to stress the connection between marketing and distribution. In 1985 these developments, designed to improve a company's overall performance and competitiveness, led to the business logistics process being defined by the Council of Logistics Management (CLM) as 'planning, implementing and controlling the efficient flow and storage of raw materials, in-process inventory, finished goods, services and related information from point of origin to point of consumption (including inbound, outbound, internal and external movements) for the purpose of conforming to customer requirements' (Mentzer et al., 2001, 16). This definition suggests that logistics is focused on optimizing processes within the firm, from development through procurement, production and transport to selling. The network of inter-company relationships involving multiple tiers of suppliers, distributors and customers, which comprise the supply chain, are considered external to the firm and, at best, a subset of logistics. Thus customer satisfaction and value beyond the efficient movement and storage of materials are not prioritized.

Supply chain logistics sought to redress this oversight by focusing upon 


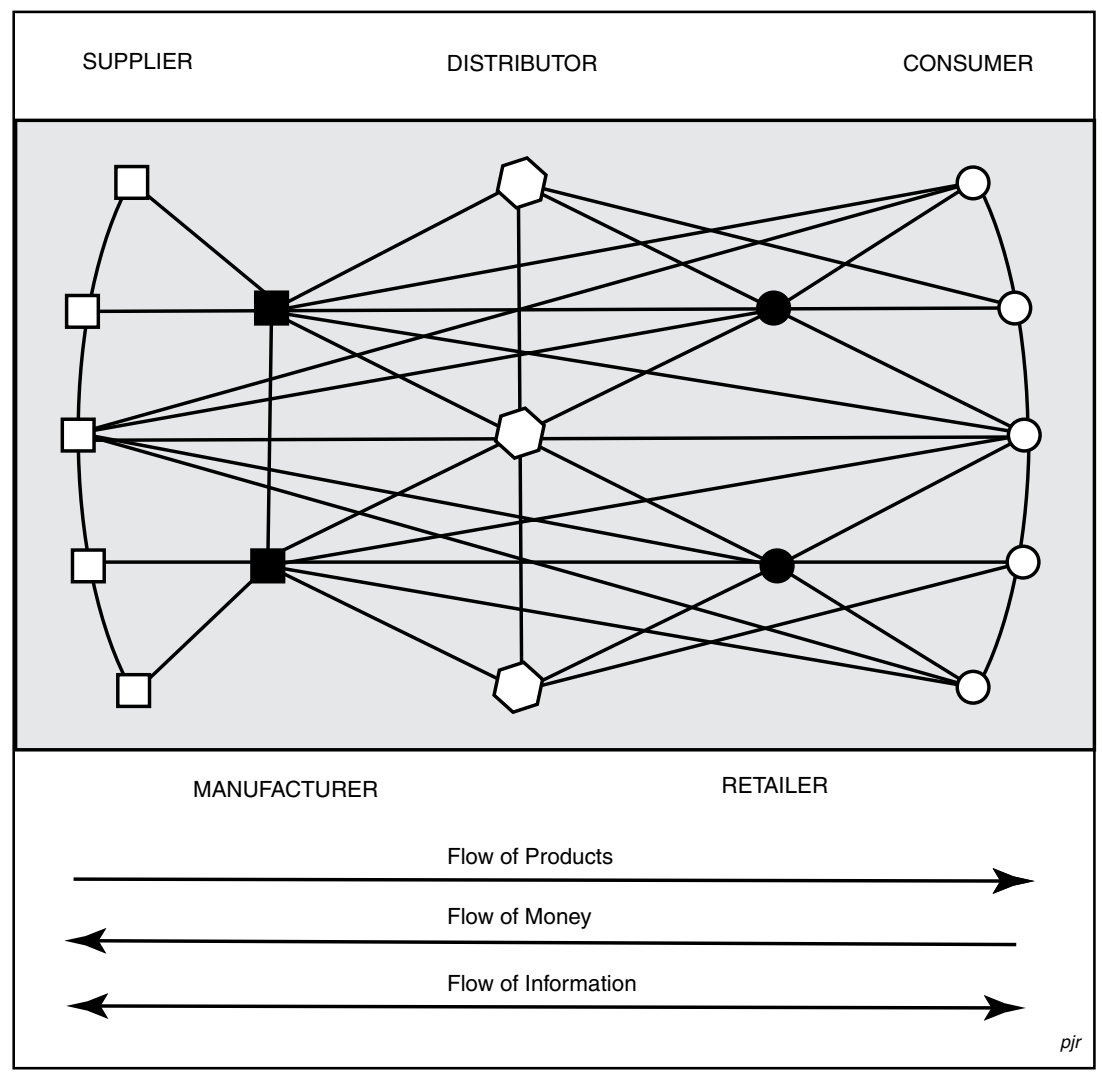

Note: Three core activities are involved in attaining the efficiency of transport activities in moving goods and creating added value: (i) the coordination of the physical flow of products through the supply chain, including waste disposal and repairs; (ii) the organization of financial flows; and (iii) the management of information flows between key players involving the transfer of intellectual property, and managerial and marketing knowledge (i.e. strategic requirements).

\section{Figure 1.2 The extended supply chain}

optimizing the efficiency of all stages involved, directly or indirectly, in fulfilling a customer's request (Figure 1.2). Linking the supplier, manufacturer, wholesaler (distributor), retailer and customer together to accommodate customer service, time compression, the globalizing of industry, and organizational integration prompted Martin Christopher (1992) to declare that supply chains, not companies, are in competition. Functions, involved in the upstream and downstream linkages between organizations 


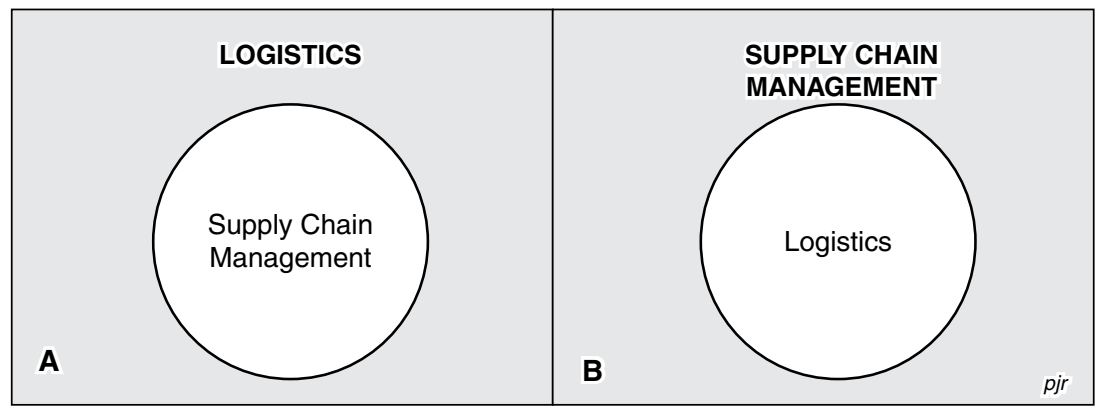

Note: (A) The traditional perspective in which supply chain management is a subset of logistics; and (B) the unionist perspective in which supply chain management subsumes logistics.

Source: Adapted from Larson and Haldorsson (2004).

\section{Figure 1.3 Changes in the relationship between logistics and supply chain management}

in the supply chain network, range from new product development through marketing and operations, to finance and customer service (Lambert et al., 1998).

The prime objective of integrating different processes, which produce financial gain through the efficient provision of products and services for the satisfaction of the ultimate customer, is to maximize the overall value created in the supply chain network. This objective has led to logistics being recast as a subset of supply chain management (SCM) that plans, sources, makes, delivers and returns commodities (Figure 1.3). In 2004 the Council of Logistics Management was renamed the Council of Supply Chain Management Professionals (CSCMP) to incorporate 'not only logistics, but also procurement, manufacturing operations, and sales/marketing functions' (MH\&L, 2004, 1). CSCMP (2012) provides a working definition of supply chain management as the process that 'plans, implements, and controls the efficient, effective forward and reverse flow and storage of goods, services and related information between the point of origin and the point of consumption in order to meet customer's requirements'.

Over time different configurations of supply chains have evolved. Looking at supply chain design and operation from the point of view of a customer's dominant buying behaviour, John Gattorna (2006, 2009) identifies four discrete configurations: (1) 'continuous replenishment', for loyal customers with a strong emphasis on long-term supplier relationships; (2) 'lean', for customers focusing on efficiency and lowest cost 


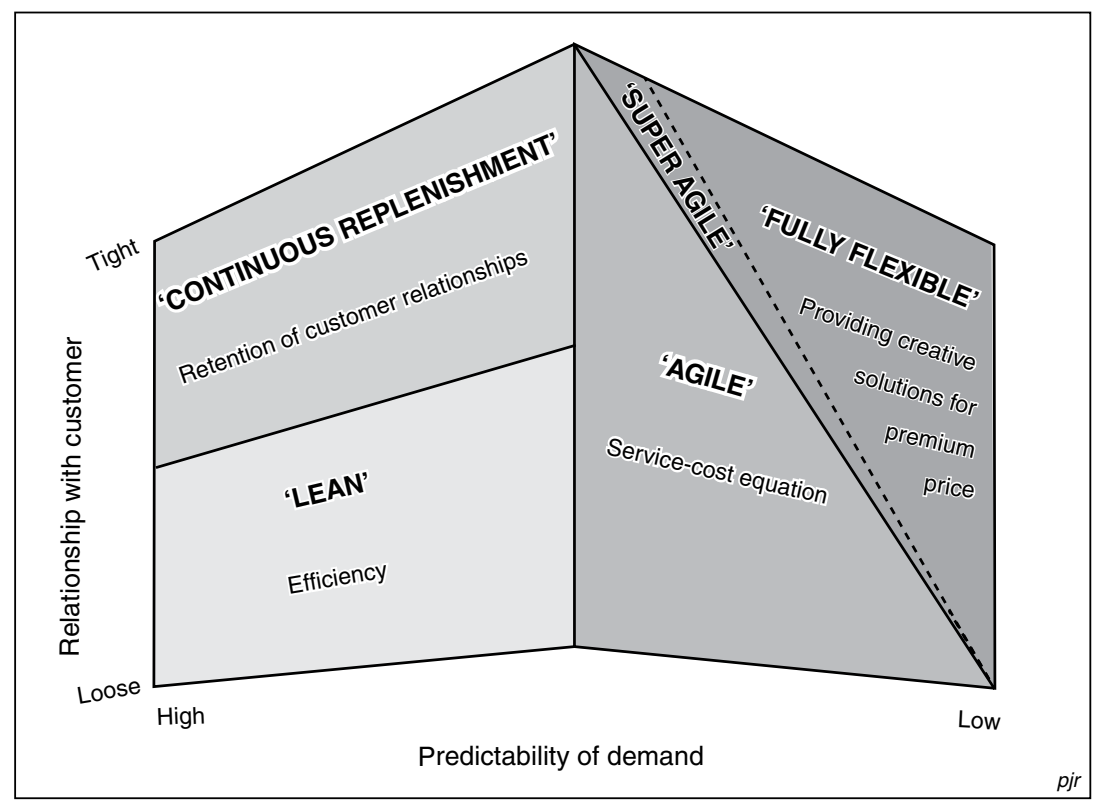

Note: 'Super-agile' has been added to cover events such as $9 / 11$ and natural disasters.

Source: Abstracted from Gattorna (2006: 43). (c) Pearson Education Limited.

Figure 1.4 Simplified version of John Gattorna's four generic supply chain types

per serve; (3) 'agile', for customers where a quick response is paramount; and (4) 'fully flexible', for customers requiring a quick-change innovative solution (Figure 1.4). The continuous replenishment and lean strategies were fashioned during a period of relative economic stability in the 1980s and 1990s. Agility and flexibility strategies have become more prized than cost efficiency in the more turbulent environment experienced during the new millennium marked by volatility and uncertainty in demand and transport costs that peaked during the Global Financial Crisis (2008-09) (Christopher and Holweg, 2011). To ensure that the four different supply chain configurations harmonize with the environment, governments have injected social needs into the equation.

Social logistics is a hybrid concept aimed at reducing energy requirements and the external effects of logistics operations on the environment arising from climate change, air quality and noise (Tanimoto, 2000). Not only does the concept cover reverse logistics, identified in the earlier 
definition of supply chain management that incorporates recycling and energy savings from the reuse of products, but it also covers green logistics, that deals with air pollution, and industrial and packaging waste. Also involved are the inspection of goods at border crossings, confirmation of regulatory compliance, tolls, taxes and duties and emergency responses to natural disasters. These concerns have focused attention on 'the setting, maintenance, regulation, and taxation by governments of the infrastructure within which companies operate' (Baudin, 2004, 17). Such matters of public policy cover managing the location of logistics facilities, information flows, institutions, people and industry to achieve a sustainable balance between economic, environmental and social objectives.

Business logistics (incorporating physical distribution), supply chain logistics and social logistics are sometimes seen as alternatives (Baudin, 2004). Since the mid-1980s these variants have also been encompassed within the broader framework of 'global logistics', so that both operational and wider public policy issues brought about by the unpacking of factories and offices to locate production tasks within industrial agglomerations in different countries can be discussed together. To distinguish this finer level of disintegration from the 'first great unbundling' that occurred between 1850 and 1914, when the railways and steamships first enabled production to be separated from consumption by cutting shipping costs, Richard Baldwin (2006) refers to the period since the mid-1980s as the 'second great unbundling'.

\section{Global Logistics}

Global logistics came into vogue from the late 1980s to cover the increased international movement of raw materials, components and finished goods associated with the 'second great unbundling' (Waters, 1988 [2003]). Soon after logistics management in a global setting was given a fillip by new political and technological realities. Key among the political actualities was the fall of the Berlin Wall on 11 November 1989 that boosted world trade, and opened up new markets and sources of raw materials. These new political realities included the increased mobility of capital that followed the liberalization of financial markets and the reduction of trade barriers after the General Agreement on Tariffs and Trade (GATT) in 1994.

Most prominent among the new technological realities have been an expanded set of transport and ICT connections that have brought people and places closer together through infrastructural developments in airports, seaports, railroads, highways and telecommunications. The personal computer, the Internet, the World Wide Web, workflow software 
with standardized protocols to coordinate a dispersed workforce, and personal and wireless technologies have been particularly significant in reducing international communication and coordination tasks (Friedman, 2008). This technological progress, coupled with the deregulation of transport and communications services, has boosted world trade because instead of following South Korea and Taiwan in building a domestic supply chain, economies such as China have industrialized by joining supply chains that have been built across borders (Baldwin, 2011). As industrial activities are divided between countries, a distinction can be made between the headquarter economy, typified by Japan, South Korea or Taiwan, and factory economies, represented by China and Thailand.

The dynamics of international fragmentation has allowed industrial corporations to fragment their entire production process into several blocs and service links and relocate them to capitalize on the locational advantages of different economies in capital or labour-intensive activities to reduce total production cost (Jones and Kierzkowski, 1990). This strategy has permitted vertical command-and-control systems to be moved horizontally offshore to facilitate the development and extension of production networks or supply chains to serve emerging markets across the world (Figure 1.5). As exemplified by the offshoring of contract manufacturing to China and the migration of business functions to India, the practice is most advanced in Asia.

Fragmentation is designed to reduce the cost of materials and production and, more or less, break-even on inventory (Figure 1.6). In moving away from a localized production site to multinational operations, transport costs have increased. This has led the management of some complex supply chains, comprising suppliers, retailers and customers, to complement the offshoring process by outsourcing their logistics activities. The logistics provider's task is to ensure that the costs involved in moving items between the production blocs are both low enough not to discourage the fragmentation process and of sufficient quality to meet the service needs of the market. Where these needs are not met, multinational corporations may return to locations closer to home (that is, near-sourcing) when the proposition that "low cost country advantage" offsets the transportation cost in supply chains' is no longer sustainable (Christopher and Holweg, 2011, 80). These developments in 'global logistics' ('global supply chains' or 'global value chains') have been captured in both single texts (Gourdin, 2001; Voortman, 2004; Mangan et al., 2008 [2012]; Gereffi and Lee, 2012; Cattaneo et al., 2013) and collections of essays (Waters, 1988 [2003], 2007; Bookbinder, 2005, 2013; Elms and Low, 2013).

Adding the word 'global' to logistics does not have any profound effect upon the subject's content other than to emphasize the importance 
A. Before fragmentation

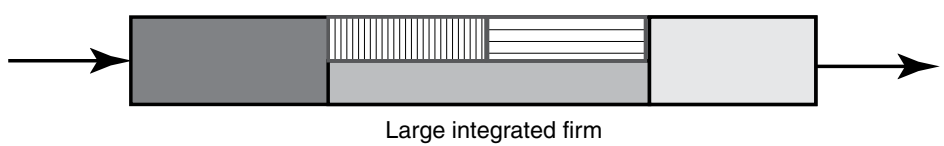

B. After fragmentation

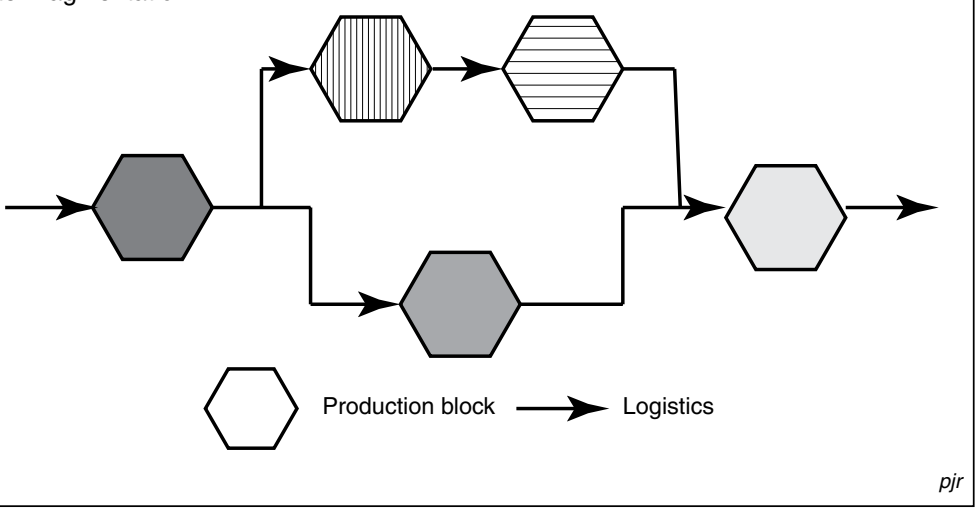

Note: (A) An industrial corporation builds an entire product within a factory. (B) The industrial corporation reduces production costs by unbundling some of its production processes and logistics service tasks according to their labour or capital-intensive characteristics.

Source: Based on Kimura and Umezaki $(2011,5)$.

Figure 1.5 The fragmentation theory: production blocks and links provided by logistics service providers

of connectedness. An obvious drawback to any uncritical adoption of this title is the underlying assumption that globalization explains almost everything by downplaying or disregarding the role and power of the local nation-state (Bookbinder and Matuk, 2009). Multinational manufacturing and retailing corporations, and increasing international trade, are widely accepted as explanatory variables of current economic trends, but globalization is still a contentious proposition.

There are arguments that globalization is not a new phenomenon, but the continuation of processes whose antecedents can be traced at least to the nineteenth century, if not back to the fifteenth. The drive towards free trade since the 1990s has echoes of the period prior to the First World War, dating from 1870, although international integration was still limited. Even if 'global' is used explicitly to describe the period in logistics 


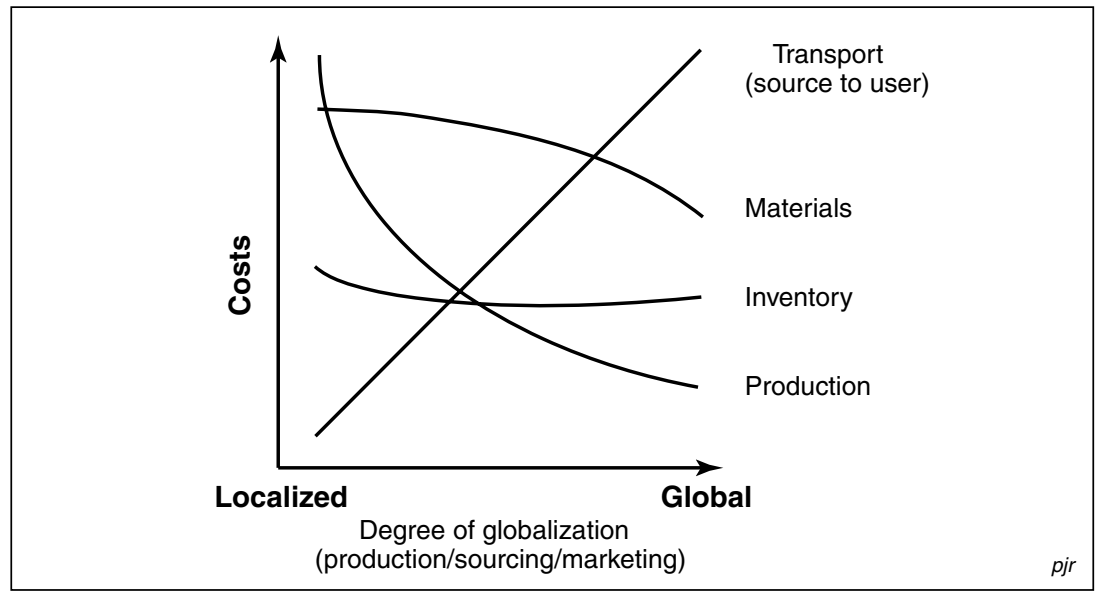

Source: Christopher $(2011,172)$. (C) Pearson Education Limited.

Figure 1.6 Trade-offs involved in switching from a localized towards a global sphere of operation

of deeper international economic integration since the $1990 \mathrm{~s}$, it should not be taken as a given. Different logistics patterns have to be tested to determine the extent to which they represent full, partial or semi-globalization (Ghemawat, 2007).

Also there is often the implicit supposition in using the term 'globalization' that economic geography is no longer relevant in a business world, where the distinction between a corporation's domestic and international markets is fading. Logistics issues within large countries such as China or India are claimed to be almost identical to those experienced by selling internationally in Europe and North America. Eye-catching, but extravagant, propositions have arisen to describe the competitive business landscape, notably: 'the world is flat', 'the end of geography' and 'distance is dead'. Even in a global virtual world, place still matters because cyberspace markets, exemplified by Google's confrontation with the People's Republic of China, are still governed by political boundaries and state laws (Quelch and Jocz, 2012,8). As a counter to globalization 'steamrolling' all other arguments, the term 'local logistics' is coined to suggest that even in a flattening and shrinking world, location is of prime importance, and distance still remains to be modified, conquered and subjugated. 


\section{Local Logistics}

This book evokes the term 'local logistics' to discuss significant developments in high-speed rail, trucking and inland waterways within the Asian-Pacific Rim that otherwise would be glossed over when examining global patterns. Already the term 'city logistics' exists to cover the logistics and transport activities of private companies within urban areas (ICL, 2013). The broader concept proposed here also encompasses logistics at other local levels such as the region, nation, province and firm. Thus, logistics in the Asian-Pacific Rim, Europe and North America, South Korea, Zhejiang Province in China, Tokyo and Chengdu Xindu Logistics Centre would all come under the same 'local' umbrella. On this reckoning many of the articles that appear in collections of essays on 'global logistics' would be classed as 'local logistics'. Even 'the global supply chain', as observed by Richard Baldwin (2013, 20), 'is not very global - it's regional'; an observation confirmed by Olivier Cattaneo et al. $(2013,3)$.

Integrating interactions between logistics within specified local areas and the global level provides an opportunity to develop a more embracive analytical framework. This framework is important because local logistics networks have become increasingly significant under a newly emerging set of competitive economic and social conditions pertaining in the world's major economic regions. Manufacturing and retailing in an increasingly interdependent world are knitted together by horizontal international linkages arising from lower freight costs, and the cutting of tariffs and quotas on trade in goods and services. A reduction in the cost of these items does not automatically result in the dispersal of economic activities (Figure 1.7). Both spatial concentration and redispersion processes can stem from the non-linear impact of transport and communications on development.

Economic activities, given limited and imperfect information, are not spread evenly, but attracted to an increasing number of urban platforms or gateways that are expanding their areas of influence by offering innovation, entrepreneurship, and an educated and skilled workforce. Capitalizing on linkages between clustered firms in the same industry within these spatial agglomerations can save transaction costs incurred when buying or selling, especially through a reduction in search and information costs. Even where redispersion occurs from agglomerations to the peripheries, it involves, as exemplified in Greater Bangkok, the deconcentration of activities within the immediate hinterland rather than decentralization to remote areas. Within the urban agglomerations and their immediate hinterlands, attention is being focused upon the adequacy of logistics and the supporting institutional infrastructure because of 


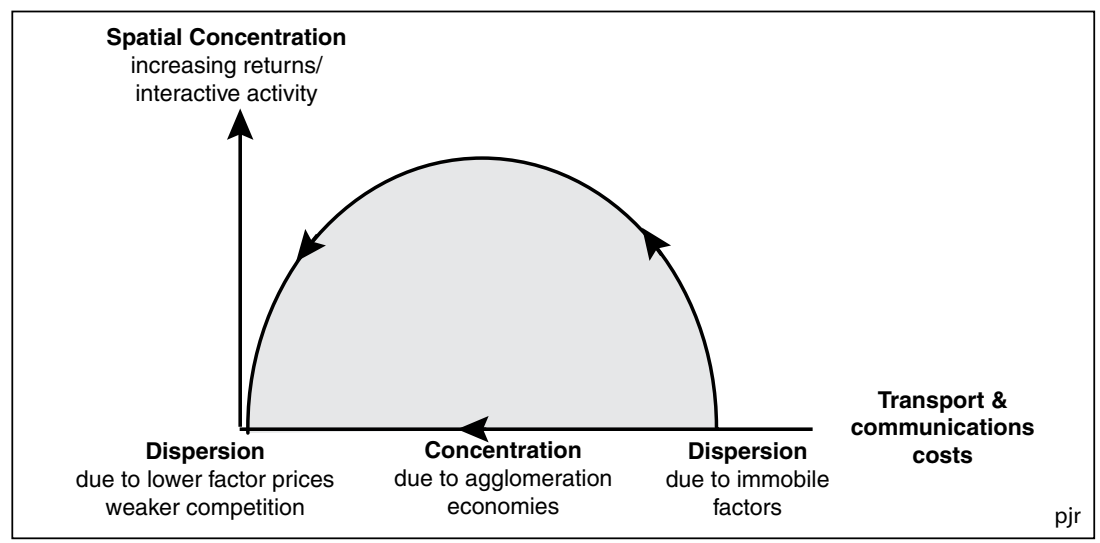

Note: The shaded area represents the degree of spatial concentration. Dispersion occurs when capital and labour, owing to lack of information, cannot respond to changes in rewards and job opportunities. Concentration stems from economies of scale, proximity to market and easy access to capital that attracts economic activities into clusters (i.e. agglomeration economies). Re-dispersion arises from congestion, reflected in wage rises, land prices, traffic jams and pollution, and the attraction of lower labour costs, that encourages some economic activities to deconcentrate to peripheral metropolitan sites or decentralize to rural locations.

Source: Based on Fujita (1999).

\section{Figure 1.7 The spatial economy is shaped by tensions between dispersive and agglomerative forces}

their significant effect upon costs, productivity and efficiency. Thus the logical outcome of the fragmentation of production on local logistics is an increasingly 'uneven', 'tilted' or 'spiky' world between and within the richest and poorest regions, nations, provinces and cities stemming from differences in infrastructure, education and governance.

Local logistics is not intended to be an end in itself. There is a need for more than a series of assertions about the nature and significance of logistics in different localities as an antidote to pronouncements by management leaders and commentators concerning the global nature of logistics. The alternative is to develop a 'third way' that integrates both global and local elements in a bid to come closer to seeing 'the world as it really is'. This third way is sought by providing a more flexible analytical framework for studying logistics that explores relationships between the global and the local, illustrated here by reference to the economic integration of the Asian-Pacific Rim. However, before developing the 'global + local' perspective, the features of the Rim's distinctive economic geography must be outlined. 


\section{THE ASIAN-PACIFIC RIM}

The Asian-Pacific Rim came to the fore after the Pacific War (1941-45) when cross-border trade, capital flows, logistics developments, and other economic and social interactions overcame political barriers. Different economic and regulatory systems have brought about closer economic integration and resurgence in the region's importance. Over time there has been a progressive shift in the Rim's industrial frontier, which has been likened by Japanese observers to a 'flying geese' formation (Kuroiwa and Kumagai, 2011). Since the 1980s the frontier has moved from the immediate post-war leadership of Japan, through the Asian newly industrializing economies (NIEs) of Hong Kong, Singapore, South Korea and Taiwan to the second-tier of Indonesia, Malaysia and Thailand. Now China is the prime focus of the 'world factory', while the frontier is shifting further west to Viet Nam, Laos, Cambodia and Myanmar, and to Bangladesh in South Asia.

Economic integration of the Asian-Pacific Rim has been facilitated by the establishment of special economic zones (SEZs) in coastal locations, together with the appreciation of Japanese currency against the United States dollar following the Plaza Accord in 1985, which prompted multinational manufacturers and retailers based in Japan to invest in facilities, training, technology and long-term business relationships within other economies within the Asian-Pacific Rim. Over time intra-regional trade has shifted from agricultural to manufactured goods, buoyed by the incorporation of the Rim's economies in expanding multinational production networks, particularly those in the motor vehicle, electrical machinery and electronics industries.

This process of fragmenting production has occurred in tandem with the Rim becoming a multi-core economy stretching through a string of mega-city platforms and industrial belts from Sapporo to Surabaya that offer agglomeration economies to multinational industrial corporations (Figure 1.8). The straight-line distance between Tokyo and Singapore $(5310 \mathrm{~km})$ is greater than that between New York and San Francisco $(4140 \mathrm{~km})$, while the Rim's geographical area, excluding Oceania (11.8 million $\left.\mathrm{km}^{2}\right)$, is larger than that of the United States $\left(9.8\right.$ million $\left.\mathrm{km}^{2}\right)$. As instanced by the Asian Financial Crisis (1997-98), the Rim's multicore economies experienced similar instabilities to those experienced in the development of the United States' 'frontier economy' during the late nineteenth and twentieth centuries, and the earlier European frontier economy in the mid-nineteenth century when the centre of manufacturing moved progressively from the United Kingdom to Germany and France (Fujita, 1999). As the latest in the line of 'frontier economies' the 


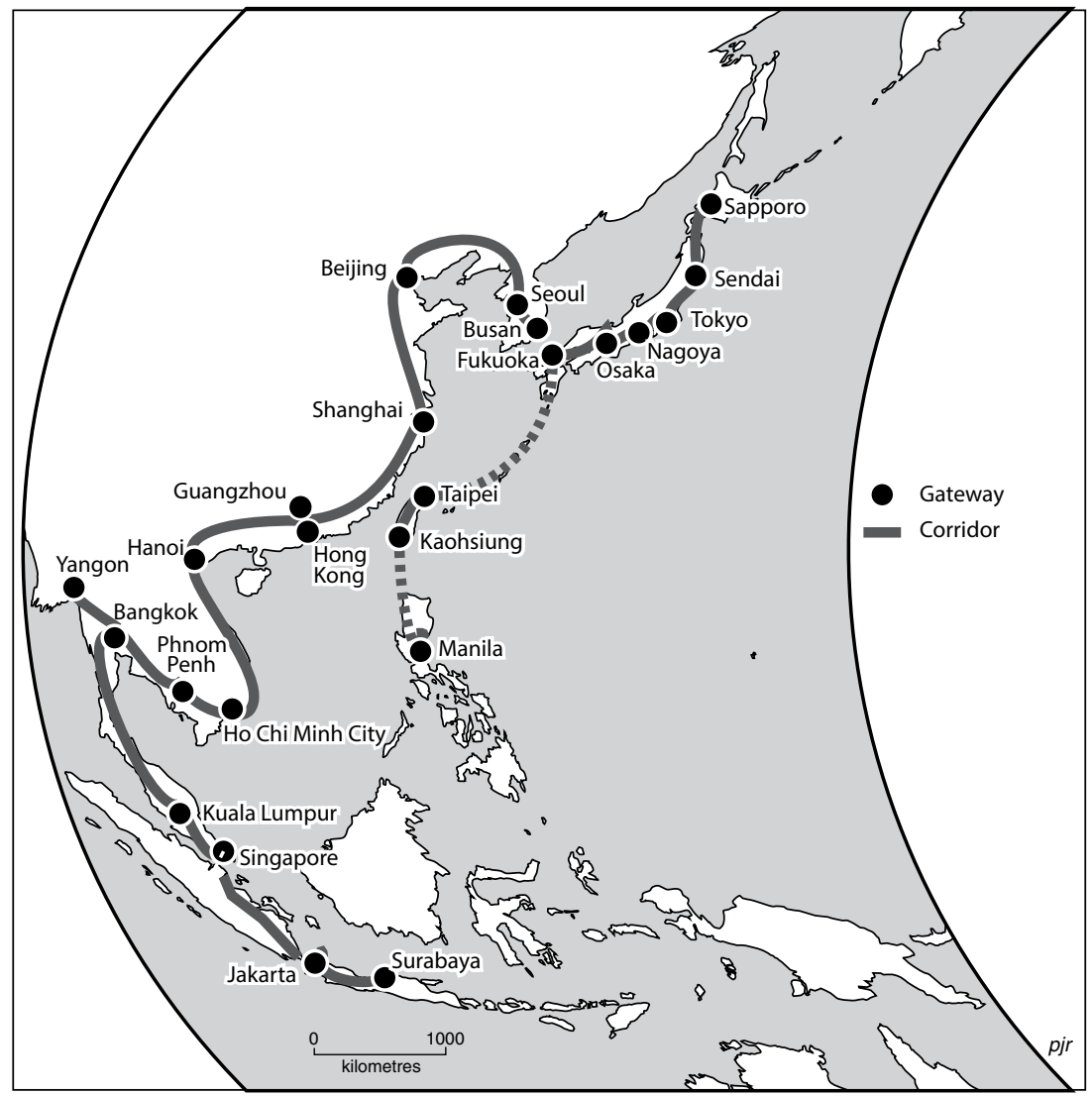

Source: Developed from Fujita (1999).

Figure 1.8 The Asian-Pacific Rim's multi-core economy

Asian-Pacific Rim does not enjoy the same level of institutional, physical and people-to-people connectivity as its mature counterparts in Europe and North America (APEC PSU, 2013a).

A 'seamless' Asian-Pacific Rim is still a long way from reality (ADB and ADBI, 2009). There is great diversity in supply chains and logistics within and between economies within the region, ranging from Singapore to Myanmar. Shortcomings are encapsulated in Peter Backhouse's (2006) catalogue of inadequacies highlighting that: (1) supply chains are increasingly influenced by the impact of lower-cost manufacturing belts due to highly fragmented, unsophisticated material flow infrastructure; (2) supply 
chain principles, including just-in-time, are being eroded by extended and unreliable lead times, and increasing inventory levels; and (3) land, sea and air freight lane capacities are being stretched to their limits. Besides inadequate infrastructure and logistics capacity, the 'across-the-border' issues of physical connectivity and the 'behind-the-border' issues arising from the inefficient clearance of goods and burdensome documentation procedures, lack of policy coordination among government agencies, variability of cross-border regulations and absence of custom-transit arrangements have an adverse effect on supply chains (APEC PSU, 2013b, 3; Goh, 2013).

The 'behind-the border' supply chain issues are compounded by some mega-cities in the Asian-Pacific Rim, notably Bangkok, Jakarta and Manila, still retaining some of their 'frontier' characteristics associated with the evasion of zoning restrictions and lax pollution controls. Nevertheless these urban platforms or gateways are leading the Rim's growth by agglomerating major industries and service functions into localized geographical clusters. These clusters enjoy scale economies or increasing returns to scale because they offer innovation, entrepreneurship and an educated workforce. This pattern of economic development has become locked into the Rim, and 'path-dependent', in the sense that technological change is essentially 'local', and reinforces and privileges existing urban economies, allowing them to stay at the cutting edge of regional progress by hosting freight distribution centres and logistics parks.

The Asian-Pacific Rim's boundary, as defined here, does not coincide with any economic grouping or trade bloc. Although the Asia-Pacific Economic Cooperation (APEC) forum established in 1989 encompasses the area and highlights the critical importance of connectivity and supply chain performance in its policy studies, its 21 members extend beyond the Asian-Pacific Rim to include Canada, Chile, Mexico, Peru and the United States, but exclude India (PwC, 2012; APEC PSU, 2013a, 2013b). This is also true of the Trans-Pacific Partnership (TPP) Agreement, which builds on the 2006 Trans-Pacific Strategic Economic Partnership Agreement (P4) between Brunei Darussalam, Chile, New Zealand and Singapore, to include Australia, Canada, Japan, Malaysia, Mexico, Peru, the USA and Viet Nam, but not China, South Korea or India. Because the transoceanic scope and composition of APEC and the TPP would detract from comparing the Asian-Pacific Rim with North America and Europe - one of the key tasks of this book - these wider definitions are not pursued here.

A narrower trade bloc, the Association of Southeast Asian Nations (ASEAN) established in 1967, now covers ten states in Southeast Asia (Brunei Darussalam, Cambodia, Indonesia, Laos, Malaysia, Myanmar, the Philippines, Singapore, Thailand and Viet Nam), but excludes China, 


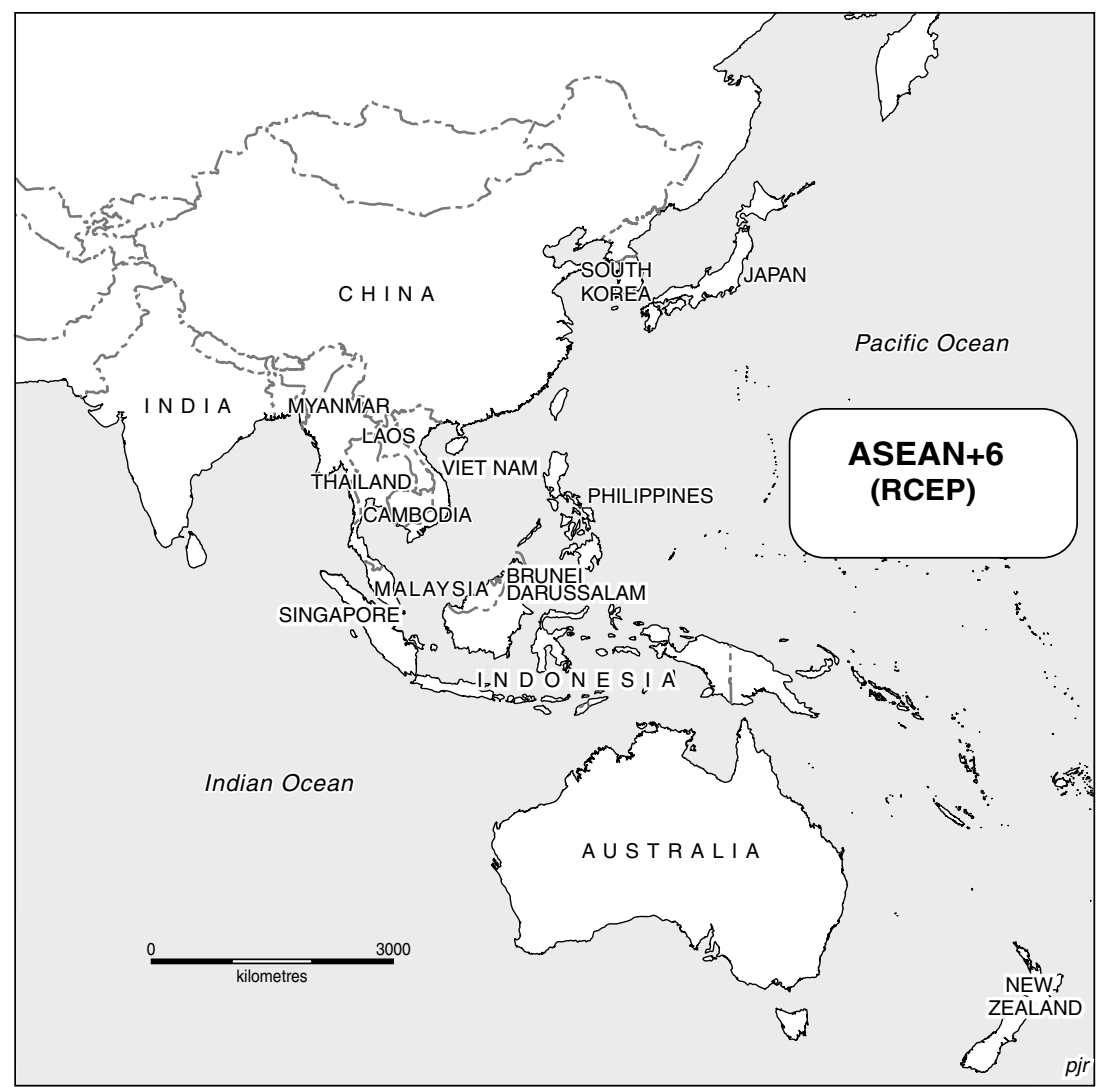

Note: The region encompasses the ten members of the Association of Southeast Asian Nations (ASEAN) - Brunei Darussalam, Cambodia, Indonesia, Laos, Malaysia, Myanmar, the Philippines, Singapore, Thailand and Viet Nam - and the group's six major trading partners comprising Australia, China, India, Japan, South Korea and New Zealand.

\section{Figure 1.9 ASEAN+6 Bloc/Regional Comprehensive Economic Partnership ( RCEP)}

Japan and South Korea in Northeast Asia (Figure 1.9). Their omission has been remedied to the extent that members of the ASEAN Free Trade Area, established in 1992, have had joint meetings with China, Japan and South Korea (ASEAN+3) since 1997. Also the annual East Asia Summit now includes Australia, New Zealand and India as members (ASEAN+6). Since 2012, moves have been initiated by ASEAN to create a regional free trade area encompassing ASEAN and its six partners into the world's 
largest trading bloc by 2015 with a GDP of US\$19.9 trillion and a population of more than 3.5 billion (Australian Government, 2012a).

Referred to as the Regional Comprehensive Economic Partnership (RCEP), the pursuit of this new trade agreement justifies Australia's inclusion with New Zealand in the wider definition of the Asian-Pacific Rim (Australian Government, 2012b). As the Government of New Zealand's (2010) first National Infrastructure Plan, according to Auckland Regional Holdings (ARH, 2010), does not recognize the many challenges and risks to the country's ports sector and supply chain, attention in this book is restricted to logistics in Australia, where federal, state and local governments are seen as playing a more active role. However a watching brief on logistics developments in India comes into calculation, particularly given the upsurge of its trade with the wider Rim (Brewster, 2012; Regmi, 2012). Stronger links with Central Asia may also prompt a rethink of even the Rim's wider boundary.

\section{'GLOBAL + LOCAL' ANALYTICAL FRAMEWORK}

These initial observations on logistics - global and local - and the Asian-Pacific Rim raise a series of issues: how can a flexible analytical framework that accommodates complex interdependencies between the global and the local be provided for investigating contemporary developments in logistics within the region? More specifically, how can both the global nature of logistics and multinational supply chain management, and its significance in different localities, be incorporated into the framework without downplaying or disregarding the importance of the local state?

In addressing these issues the global and local analytical framework developed here allows the incorporation of both international and local networks and linkages (Figure 1.10). Of pivotal importance is the recognition that urban gateway locations situated in complex networks are both global and local (Dick and Rimmer, 2003). These gateways integrate and mediate the two-way global and local flows of goods, people, information and capital. Global flows occur within the 'hinterworld' between gateways (Taylor, 2001; Taylor and Walker, 2004). Each gateway is also linked to local hinterlands by reciprocal flows concentrated along corridors within provinces or nations A and B. Provision is made for global-local interactions and local-global interactions that bypass gateways (for example, resource flows).

Many actors are involved in global and local linkages, and networks ranging from civil society organizations through consumers, labour and states to firms (public enterprises, small and large national firms, 


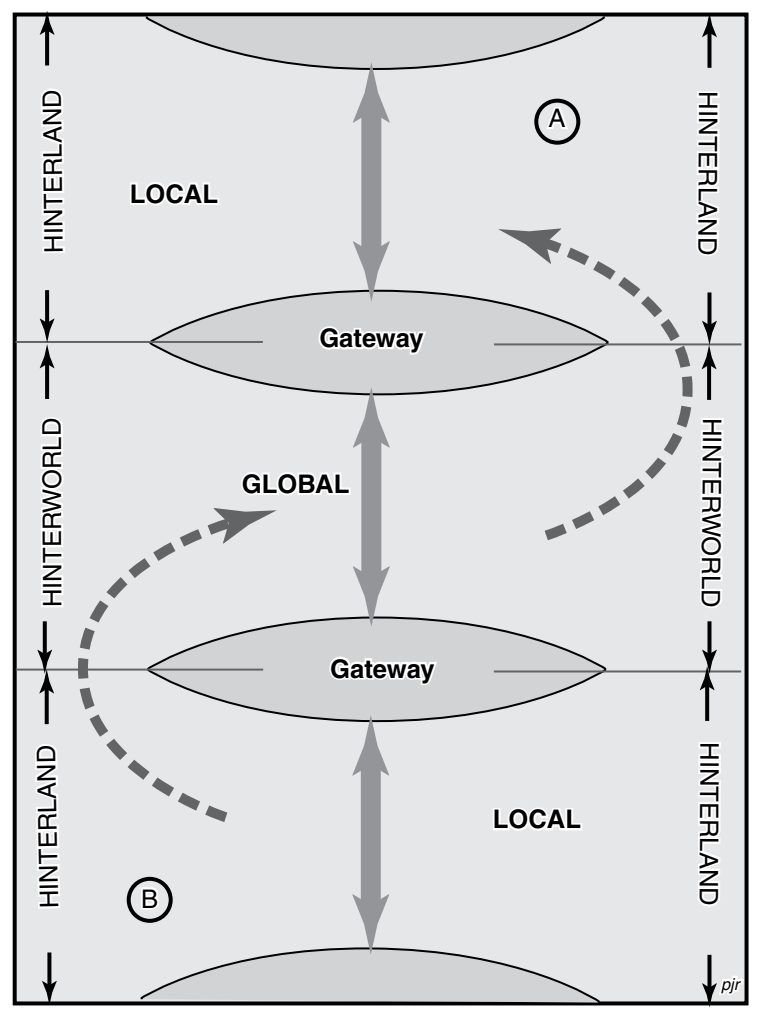

Note: Interactions are shown in the hinterworld between the gateways of regions A and $\mathrm{B}$ together with flows within their respective hinterlands, including resource flows (dotted line) that do not pass through the gateways.

Source: Developed from Dick and Rimmer (2003, xvi).

Figure 1.10 Global and local analytical framework

and multinational and global corporations). Ideally, one would like to examine the interrelationships between all actors, but in seeking to unlock global and local perspectives on logistics and supply chain management, the potential cast is narrowed to the leading roles played by states and firms, and the relationships between them: state-firm, firm-firm and state-state (Dicken, 2007).

Within this narrowed compass the emphasis is further tapered to focus on the 'local' state and large corporations, although public enterprises, small and larger national firms will enter and exit depending on the particular scene. Large corporations are pared down, given the focus on 


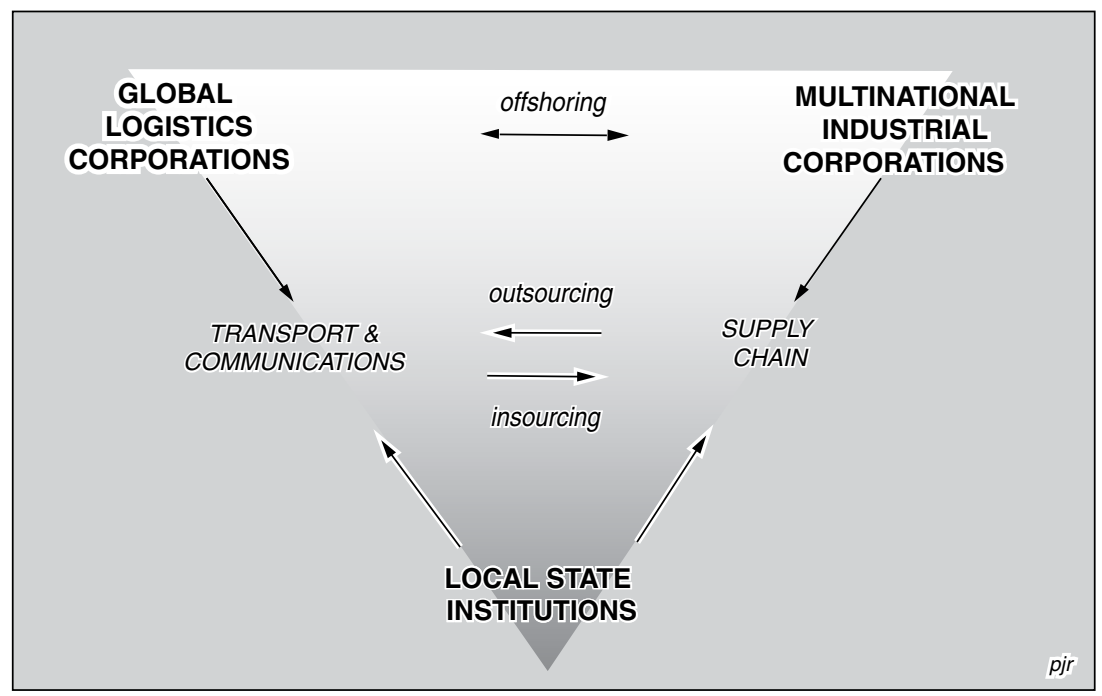

Figure 1.11 Interactions between key players within the triangular framework of interest

logistics, to distinguish two separate, but complementary, networks - multinational industrial corporations and global logistics corporations - that, together with the local state, form this book's triangular framework of interest (Figure 1.11):

- Multinational industrial corporations (MICs) are engaged in the industrial goods transformation network, which extends from natural resources through resource extraction, material processing, parts and components, assembly, wholesale, retail and customers to recycling; the corporations seek to reduce transaction costs in their supply chains that spread across national borders through optimal production, distribution, and location of factories and retail outlets.

- Global logistics corporations (GLCs) operate sea, land and air transport and communications networks that stretch across the globe to provide intermodal freight transport, and just-in-time door-to-door operations for both high-volume and small-lot shipments to meet customer needs and differentiate themselves from rivals.

- Local state institutions (LSIs) make economic planning decisions, involving infrastructure, special economic zones, preferential trade agreements and customs procedures, and market regulation and, 
in varying degrees, collaborate with the private sector in ways that affect the architecture of supply chains of both multinational manufacturing and retailing corporations, and the dynamics of global logistics corporations within regional, national, provincial and metropolitan spheres.

Within this interactive framework prime attention is focused on the cross-industry intersection between the coterminous production and logistics networks, where the two actors seek to decrease costs involved in selling in different locations; these costs arise from moving goods, people and information; tariff and non-tariff barriers; and cultural differences (Hamilton, 2005; Rimmer and Hamilton, 2008; Isono, 2011).

At the firm and product level the emphasis within the multinational industrial corporations has been on the supply chain, rather than on the global transport and communications network as such (Figure 1.12). This focus on the supply chain leads to an emphasis on the purchasing systems

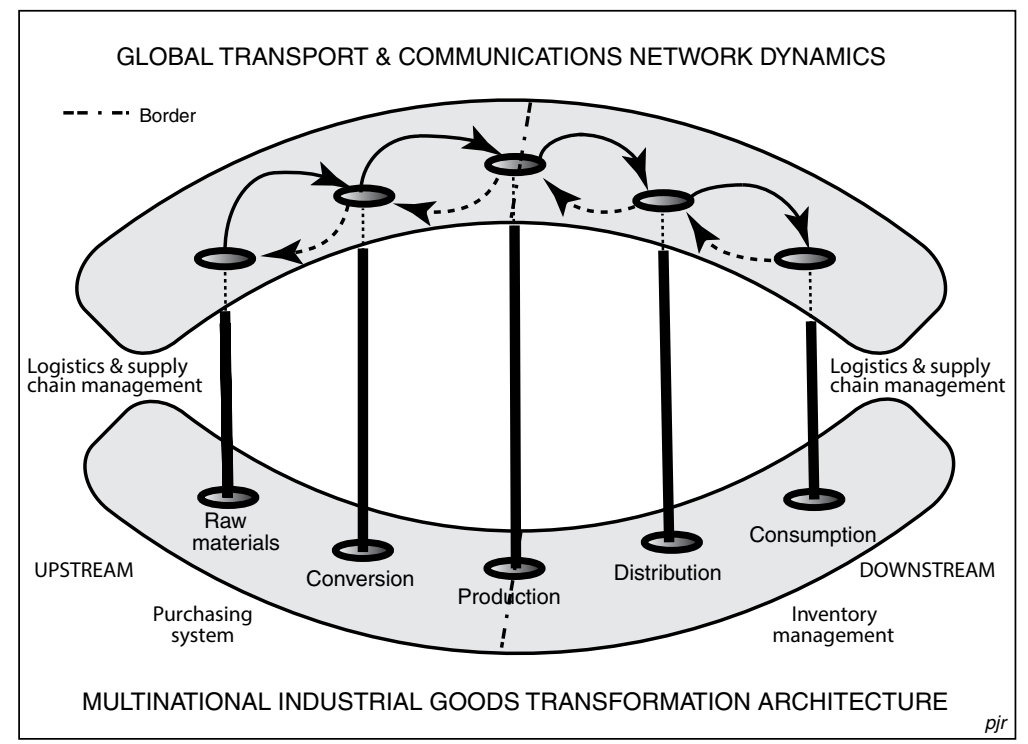

Note: The diagram reflects the relationship between the 'space' of places and the 'space' of flows. Inserting the border leads to the distinction between industrial agglomeration within a country and international fragmentation across countries.

Figure 1.12 Relationship between the multinational industrial goods transformation architecture and the global transport and communications network's dynamics 
and inventory management, and inbound and outbound traffic flows. Nevertheless transport and communications network attributes have to be taken into account because, as goods pass through the supply chain, they affect the structure of costs, timing of shipments and conditions of consignments (McMillan, 2009). These attributes underline that global transport and communications infrastructure is of paramount importance to the management of supply chains through its role in connecting fragmented domestic and international production facilities.

Multinational manufacturers and retailers can either provide their own transport and communication needs in-house or, as noted, outsource these services to global logistics corporations. Alternatively, multinational manufacturers and retailers can in-source logistics services by allowing global logistics corporations to act within their organization. This firm focus makes it difficult to integrate the multinational production network based on competition between supply chains with those in the global transport and communications network that favour cooperation between modes.

At a sectoral level it is not possible to have seamless connections between geographically dispersed production networks without looking at the dynamics of the global transport and communications network. Comprising companies (related or unrelated to each other), this transport and communications network propels goods, especially parts and components, across the world; the focal point being on global logistics, with a secondary emphasis on accommodating numerous supply chains across different industries. Corporations within both the production and transport and communications networks create value in the opposite network. The global transport and communications network is essential for the operation of individual multinational industrial corporations. The network itself creates value for transport and communications corporations (for example, airlines and telecommunications).

Planning and policy decisions by local state institutions still influence these world-spanning activities through 'tariffs, tolls, visas, trading quotas and restrictions on border passage', despite international agreements by the International Monetary Fund (IMF), World Trade Organization (WTO) and the World Bank providing the rules and regulations for the capitalist market economy (Walker, 1999, 13). Local institutional control over the gateways governing global and local flows of goods, people, information and money is therefore critical for operators of both global logistics and multinational production networks. 


\section{OVERVIEW}

The stage is now set for investigating global logistics patterns in Part I of this book, and local logistics processes and policy aspects in the Asian-Pacific Rim within Part II, before widening the region's definition in Part III to accommodate local logistics policies in Australia, and going beyond the Rim's confines to discuss connections with India.

Part I on global logistics examines the Asian-Pacific Rim's position in the world economy by exploring a range of spatial patterns. Chapter 2 analyses the supply chains of multinational manufacturers and retailers, and the extent to which they rely on global logistics corporations, by defining and illustrating the role of third-party logistics providers. Also the global hub-and-spoke system is developed as a yardstick for examining shipping, air transport and telecommunications patterns. Chapter 3 outlines global maritime flows of bulk, liquid and general cargoes before concentrating upon the forces shaping container shipping and port dynamics in the twenty-first century, including the importance of strategic alliances, with particular reference to key shipping companies and terminal operators. Chapter 4 analyses 'global' air cargo and air passenger services, including the significance of strategic alliances and airport infrastructure. Special attention is then paid to the role of airlines as information systems. This leads to a more general discussion of information and telecommunications systems underpinning both air and sea-land transport. Chapter 5 draws upon the data from the preceding chapters on shipping, airline and telecommunications networks to develop the concept of the global 'network of networks'.

Part II explores aspects of local logistics processes in the Asian-Pacific Rim. First, Chapter 6 offers a regional overview by examining the Rim's gateways and corridors. Then Chapter 7 outlines the development of logistics policy within Japan with reference to the activities of key multinational producers and global logistics corporations, and discusses how logistics concepts and technologies are being fashioned and transferred to Southeast Asia to promote greater regional integration. Chapter 8 surveys the spatial structure of the South Korean economy since the Korean War (1950-53) and the emergence of multinational manufacturers, before examining the development of national logistics policies, the appearance of a major South Korean-based global logistics corporation and the importance of logistics in place marketing, with special reference to the gateways of Incheon, Busan, Gwangyang Bay and Gunsan. Chapter 9 demonstrates that any understanding of logistics policy in China requires knowledge of changes in the country's geography and its history over the past 100 years. With this background, the reshaping of China's logistics 
infrastructure under President $\mathrm{Hu}$ Jintao's government during the first decade of the twenty-first century is discussed, before looking ahead to the issues that need to be addressed by his successor, President Xi Jinping's government. Chapter 10 examines the raft of policies designed to bring China, Japan and Korea into an integrated Northeast Asian logistics framework.

In Part III the narrow definition of the Asian-Pacific Rim is widened to encompass Australia's logistics policy, before considering the growing emphasis on interconnecting the Rim with India. Chapter 11 tracks the rise, fall and renaissance of Australia's global logistics corporations, and the way in which newcomers are using connections with the Rim as a springboard to emulate the global reach of the country's earlier logistics leaders. Then in Chapter 12 the proposed linkages between the Rim and India are addressed.

An Epilogue considers how the global hub-and-spoke model can be revamped to incorporate Eurasia, whose economic potential will remain untapped without improvements to, and maintenance of, physical structures, equipment and facilities, and policy, regulatory and institutional frameworks. Extending the Asian-Pacific Rim's logistics networks to meet the rising demand for trading with Central Asia's geographically isolated, inland and remote areas and landlocked countries is seen as a counterweight to the region's reliance on export markets in Europe and North America. Looking ahead to 2050, consideration is given to the likely nature of the revamped hub-and-spoke network by exploring scenarios for both global logistics and local logistics, and the prospects for combining the two. This leads to a reflection on this book's conceptual framework and the need to reformulate the approach for studying multinational industrial corporations engaged in manufacturing and retailing. 